\title{
Büyük ve Orta Boy İşletmeler İçin Finansal Raporlama Standardı (BOBİ FRS) Kapsamında Nakit Akış Tablosu Düzenlenmesinde Doğrudan - Dolaylı Yöntem Tartışması ve Karşılaştırmalı Örnek Bir Uygulama
}

\author{
Serkan ÖZDEMIR ${ }^{1}$
}

$\ddot{O} z$

İşletmeler gelecek planları yapabilmek ve yönetim kararları alabilmek; şirket ortakları, yatırımcılar ve diğer üçüncü şahıslar ise ișletme hakkında analizler yapabilmek için doğru ve detaylı finansal bilgiler içeren finansal tablolara ihtiyaç duyarlar. Nakit akış tablosu BOBİ FRS tabi işletmelerin düzenlemek zorunda oldukları en önemli finansal tablolardan biridir. Nakit akım tablosu "Doğrudan" ve "Dolaylı" yöntemlerden biri kullanılarak düzenlenebilmektedir. Literatürde nakit akım tablosunda doğrudan yöntemin kullanılmasının, ilişkili taraflar açısından daha faydalı olacağına dair birçok çalışma bulunmaktadır. Fakat buna rağmen anlaşılabilir sade yapısı, hazırlanmasının kolay olması ve işletmelerin kamuoyu ile fazla finansal bilgi paylaşmama istekleri gibi sebeplerle, dolaylı yöntemin daha yaygın olarak kullanıldığı tespit edilmiştir. Uygulama çalışmasında doğrudan yöntemle hazırlanmış nakit akış tablosunun "Esas Faaliyetlerden Nakit Akışları" bölümünde, dolaylı yöntemle hazırlanmış nakit akış tablosuna göre daha detaylı finansal bilgilere yer verildiği görülmektedir. Ayrıca dolaylı yöntemle hazırlanan nakit akım tablosunun daha sade ve anlaşılır bir yapıya sahip olduğu görülmektedir. Bu durum, dolaylı yöntemin işletmeler tarafından daha çok tercih edilmesine ait yukarıda belirtilen sebepleri desteklemektedir. Fakat her iki yöntemin "Yatırım Faaliyetlerinden Nakit Akışları" ve "Finansman Faaliyetlerinden Nakit Akışları" bölümlerinde, aynı finansal bilgilere yer verilmekte ve yöntemler arasında fark bulunmamaktadır.

Anabtar Kelimeler: BOBİ, BOBİ FRS, Nakit Akış Tablosu, Doğrudan Yöntem, Dolaylı Yöntem

Discussion of Direct - Indirect Method in Organization of Cash Flow Table under the Financial Reporting Standard for Large and Medium Sized Enterprises (FRS for LMEs) and a Comparative Example Application

\begin{abstract}
Businesses can make future plans and make management decisions; company partners, investors and other third parties need financial statements with accurate and detailed financial information to be able to analyze the business. Cash flow statement is one of the most important financial statements that the companies subject to FRS for LMEs have to issue. The cash flow table can be compiled using one of the "Direct" and "Indirect" methods. There are many studies in the literature that using direct method in cash flow statement will be more beneficial for related parties. However, it has been determined that the indirect method is more widely used due to its understandable simple structure, easy preparation and the desire of enterprises not to share much financial information with the public. In the application study, in the cash flow table of the main operation section, the cash flow table prepared by the direct method shows more detailed financial information than the cash flow table prepared by the indirect method. In addition, it is seen that the cash flow table prepared by indirect method has a simpler and clearer structure. This situation supports the above-mentioned reasons why the indirect method is more preferred by the enterprises. However, the same financial information is included in "the cash flows from investment activities" and "cash flows from financing activities" of both methods and there is no difference between the methods.
\end{abstract}

Keywords: LMEs, FRS for LMEs, Cash Flow Statement, Direct Method, Indirect Method

Atıf İçin / Please Cite As:

Özdemir, S. (2020). Büyük ve orta boy işletmeler için finansal raporlama standardı (BOBİ FRS) kapsamında nakit akış tablosu düzenlenmesinde doğrudan - dolaylı yöntem tartışması ve karşılaştırmalı örnek bir uygulama. Manas Sosyal Arastirmalar Dergisi, 9(1), 373-385.

\footnotetext{
1 Doç. Dr. -Bursa Teknik Üniversitesi, İnsan ve Toplum Bilimleri Fakültesi, Uluslararası Ticaret ve Lojistik Bölümü, serkan.ozdemir@btu.edu.tr - ORCID: 0000-0002-4493-3588
} 


\section{Giriş}

Kamu Gözetimi Kurumu(KGK) tarafindan 29 Temmuz 2017 tarihli ve 30138 Sayllı Mükerrer Resmi Gazete'de yayımlanan "Büyük ve Orta Boy İşletmeler İçin Finansal Raporlama Standardı Hakkında Tebliğ" ve eki "Büyük ve Orta Boy İşletmeler İçin Finansal Raporlama Standardı(BOBİ FRS)" ile ilgili KGK internet sitesindeki duyuruda şu anda ülkemizde mevcut muhasebe ve finansal raporlama standartları çok öz bir şekilde açıklanmıştır (Arar, 2018, s. 8-9). Bunun yanı sıra, BOBİ FRS’de, AB Direktifindeki istisnalardan faydalanılarak orta ölçekli işletmelerin, büyük işletmelerin tabi olduğu bazı yükümlülüklerden muaf tutulması öngörülmüştür (Doğan, 2018, s. 116).

BOBİ FRS, bağımsız denetime tabi olup Türkiye Finansal Raporlama Standartları(TFRS) uygulamayan işletmelerde Muhasebe Sistemi Uygulama Genel Tebliğleri(MSUGT) ve İlave Hususlar'ın yerini alacaktır. Diğer bir ifadeyle, bağımsız denetime tabi olup TFRS uygulamayan şirketlerin Türk Ticaret Kanunu(TTK) uyarınca genel kurullarına sunulacak finansal tablolarının hazırlanmasında esas alınacak finansal raporlama çerçevesi BOBİ FRS olacaktır. Ayrıca, BOBİ FRS'nin genel olarak Kamu Yararını İlgilendiren Kuruluşlar(KAYİK) dışındaki bağımsız denetime tabi tüm şirketlerin bağımsız denetimlerinde kıstas oluşturacak olması sebebiyle uluslararası standartlarda bir finansal raporlama ve bağımsız denetimin sağlanması açısından ülkemiz adına önemli bir adım olacaktır. BOBİ FRS, 1/1/2018 tarihi ve sonrasında başlayan hesap dönemlerinde uygulanmak üzere, yayımı tarihinde yürürlüğe girmiştir (Arar, 2018, s. 8-9).

BOBİ FRS seti hem MSUGT’un, hem de TFRS'lerin bazı özelliklerini içerisinde barındırmaktadır. Diğer bir ifadeyle, BOBİ FRS ile birlikte mevcut muhasebe düzeni TFRS ilke ve uygulamalarına biraz daha yakınsamıştır. Ancak yine de TFRS seti ile tam uyum söz konusu değildir (Öztürk, 2017, s. 597). Örneğin BOBİ FRS'ye tabi şirketlerin asgari olarak düzenlemesi zorunlu olan tablolar standardin "Kavramsal Çerçeve Finansal Tablolar" bölümünde (a) Finansal Durum Tablosu (b) Kâr veya Zarar Tablosu (c) Nakit Akış Tablosu (ç) Özkaynak Değişim Tablosu ve (d) Dipnotlar olarak tanımlanmıştır (BOBİ FRS: 1). BOBİ FRS'de tanımlanmış finansal tablo sepeti ile TFRS'de tanımlanmış finansal tablo sepeti karşılaştırıldığında, TFRS'de tanımlanmış "Diğer Kapsamlı Gelir Tablosu”nun BOBİ FRS standardında tanımlanmadığı görülmektedir.

BOBI FRS ve TFRS'de yer alan finansal tabloların içerikleri incelendiğinde bașka farklara da rastlamak mümkündür. Örneğin BOBİ FRS Bölüm 2'de açılanan Nakit Akış Tablosu'nun hangi yönteme göre (doğrudan-dolaylı yöntem) düzenleneceğine dair herhangi bir hüküm veya tavsiye bulunmamaktadır. Oysa TFRS'de bulunan "TMS 7 Nakit Akış Standardı" incelendiğinde 19'uncu maddede "İslletmelerin, esas faaliyetlerden nakit akışlarm raporlarken doğrudan yöntemi kullanmalarn tessvik edilir." ibaresi yer almaktadır. Tespit edilen bu farklılık çalışmanın temel dayanağını oluşturmaktadır.

Çalışmada öncelikle, BOBİ FRS'yi kullanan veya kullanacak olan işletmelerin nakit akış tablolanını düzenlerken tercih edecekleri "Doğrudan" veya "Dolaylı" yöntemlerin avantaj ve dezavantajlarının belirlenmesi amaçlanmıştır. Çalışmanın uygulama bölümünde ise, aynı örnek işletme üzerinden hem doğrudan yönteme göre, hem de dolaylı yönteme göre düzenlenecek nakit akış tabloları yoluyla, işletmeler için bir uygulama rehberinin oluşturulması ve karşılaştırma ortamının sağlanması amaçlanmıştır.

\section{BOBİ FRS'ye Göre Nakit Akış Tablosu}

Nakit akış tablosu, döneme ilişkin nakit akışları esas faaliyetlerden, yatırım faaliyetlerinden ve finansman faaliyetlerinden kaynaklanan nakit akışlarının sunulduğu bir tablodur (BOBİ FRS, s. 13). Bir başka tanıma göre ise, işletmenin bir raporlama dönemi içindeki nakit veya nakit benzerlerindeki giriş ve çıkışları, bunların kaynaklarını ve kullanım yerlerini gösteren tablodur (Arar, 2018, s. 22).

Nakit, işletmedeki nakit ile vadesiz mevduatı ifade eder. Nakit benzerleri, tutarı belirli bir nakde kolayca çevrilebilen ve değerindeki değişim riski önemsiz olan kısa vadeli ve yüksek likiditeye sahip yatırımlardır. Nakit benzerleri, yatırım veya diğer amaçlardan ziyade kısa vadeli nakit taahhütlerinin yerine getirilmesi amacıyla elde tutulur. Bir yatırım kısa vadeye (örneğin edinim tarihinden itibaren üç ay veya daha kisa bir vadeye) sahip olduğunda genellikle nakit benzeri olarak nitelendirilir (Arar, 2018, s. 23).

Nakit akış tablosu Şekil 1'de de görüldüğü gibi Esas, Finansman ve Yatırım faaliyetleri konusundaki nakit akışları hakkında bilgi vermektedir. 


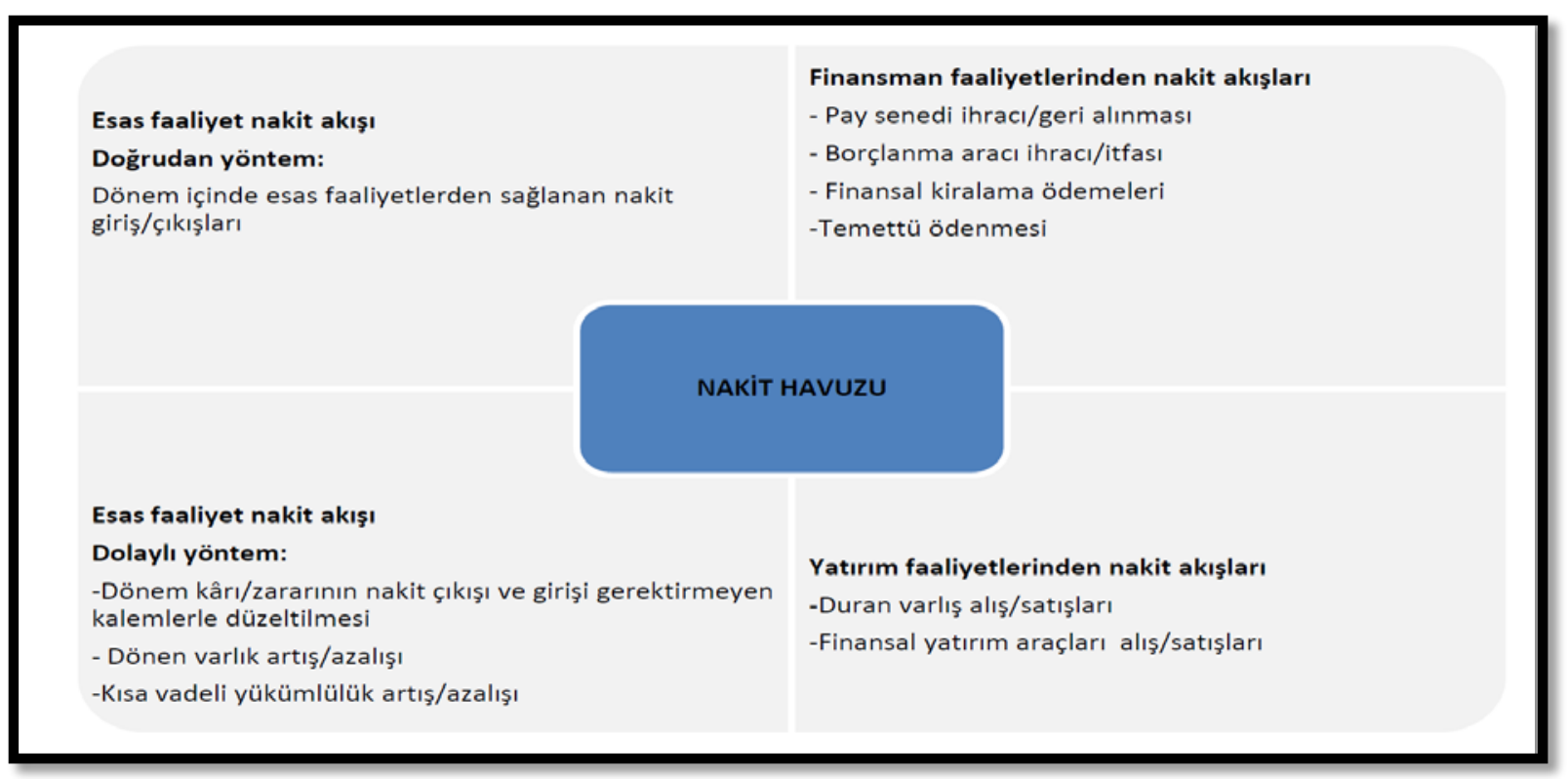

Şekil 1.Nakit Akıış Tablosu Faaliyet Türleri (Arar, 2018, s. 22).

\section{a) Esas Faaliyetlerden Kaynaklanan Nakit Akışları}

Esas faaliyetler, bir işletmenin baslat yaratan ana faaliyetleridir. Aynca işletmenin yaturm ve finansman faaliyeti olarak nitelendirilmeyen diger faaliyetleri de esas faaliyet olarak kabul edilir. Esas faaliyetlerden kaynaklanan nakit akışlar, genellikle etkileri kâr veya zarara yansittlan işlem ve olaylarn sonucu olarak ortaya ģıkar (BOBİ FRS, s. 13).

Bu bölümdeki nakit akışları Doğrudan veya Dolaylı yöntemlerden biri kullanılarak sunulur.

Eğer işletme doğrudan yöntemi kullanıyorsa, gayri safi nakit girişleri ve gayri safi nakit çıkışları ana gruplar halinde sinıflandırlarak ayrı olarak sunulur (BOBİ FRS, s. 13).

Doğrudan yöntemde esas faaliyetlerden kaynaklanan nakit gitisleri; mal satıslarndan, hizmet sunumundan, arachllk, faaliyetlerinden, diğer esas faaliyetlerden sağlanan nakit girişleri ve benz̨eri şekilde gruplandirlarak, gösterilebilir. Bu tür nakit girisllerinin hesaplanmasinda, ilgili esas faaliyetlerden sağlanan safi hasllat tutarna bu faaliyetlerden kaynaklanan alacaklardaki azalsslar eklenir, artıslar ise bu tutardan indirilir (BOBİ FRS, s. 13).

Doğrudan yöntemde esas faaliyetlerden kaynaklanan nakit ç1kışlant ise, satılan mal maliyetlerine, bizmet maliyetlerine, faaliyet giderlerine ilişkin nakit çıkışlar ve benzeri șekilde gruplandirlarak gösterilebilir. Bu tür nakit çlkışlarmm hesaplanmasinda ise satışlarn maliyeti ve ilgili diğer kalemlerden hareket edilebilir. Bu kalemlere iliskin tutarlara stoklardaki artş̧larn, almlardan kaynaklanan borçlardaki az̧alşlarn eklenmesi; bu tutarlardan amortisman giderleri ve tabakkuk etmis ancak ödenmemis giderler gibi nakit çıkıș gerektirmeyen giderlerin, almmlardan kaynaklanan borçlardaki artı̧larn, stoklardaki a ąalşlarm indirilmesi gerekir (BOBI FRS, s. 13).

Dolayl yöntemde, esas faaliyetlerden kaynaklanan nakit akışlarmm gösterimine vergi öncesi kârdan, dï̈er bir ifadeyle Dönem Kâr veya Zararı kaleminden bașlanır. Ardindan, Dönem Kâr veya Zaran kalemi aşağıdaki unsurlarn etkilerine göre dïzeltilir (BOBİ FRS, s. 13):

a) Nakit akış yaratmayan kalemler (amortismanlar, karşıllklar, ertelenmis vergiler, tahak.kuk etmis ancak henüz, nakit olarak tabsil edilmemis gelirler ile ödenmemis giderler, kur farklarndan kaynaklanan gerçekleșmemiş kazanc veya kayiplar, peșin ödenmiş giderlerin dönemde tabakkuk eden kisımlar, özkaynak yöntemine göre mubasebeleştirilen işstiraklerin dağıtılmamış kârlarndan işletmeye düssen paylar gibi),

b) Stoklarda ve esas faaliyetlere ilişkin alacak ve borçlarda dönem içerisinde meydana gelen değĭsik likkler ve

c) Yatırm veya finansman faaliyetlerinden kaynaklanan nakit akışı olusturan kalemler (BOBİ FRS, s. 14). 


\section{b) Yatırım Faaliyetlerden Kaynaklanan Nakit Akışları}

Yaturm faaliyetleri, uzun vadeli varlklarn ve nakit benzerlerine dâbil edilmeyen diğer yaturmlarn edinimi ve elden gıkarlmasıdrr. Yalmıża Finansal Durum Tablosu'nda bir varluğn kayda alınmasina neden olan harcamalar yatırm faaliyetinden kaynaklanan nakit çıkıšl olarak simflanderlabilir (BOBİ FRS, s. 14).

\section{c) Finansman Faaliyetlerden Kaynaklanan Nakit Akışları}

Finansman faaliyetleri, ișletmenin özkaynaklarmm ve yükümlülüklerinin tutarnda ve içeriğinde değgşikliğe neden olan faaliyetlerdir (BOBİ FRS, s. 14).

\section{Literatürde Doğrudan ve Dolaylı Yöntem Tartışması}

Literatür incelendiğinde her iki yöntemin kullanımını destekleyen birçok görüşün bulunduğu tespit edilmiştir. Fakat çalışmaların, doğrudan yöntemin kullanımını destekleyen görüşlerde yoğunlaştı̆̆ı belirlenmiştir.

TMS 7 Nakit Akış Tablosu standardında doğrudan yöntemin kullanılması tavsiye edilmiştir. Doğrudan yöntemin gelecekteki nakit akışlarının tahmininde faydalı olabilecek nitelikte ve dolaylı yöntemle elde edilemeyen bilgileri sağladığı belirtilmiştir (TMS, 7: 5).

Yapılan birçok çalışmada doğrudan yöntemin gelecekteki nakit akışlarının tahmininde dolaylı yöntemle karşılaştırıldığında daha kaliteli, detaylı ve faydalı bilgiler sağladığı tespit edilmiştir. Yöntem özellikle satış, satılan malın maliyeti ve faaliyet giderlerine ilişkin nakit akımları, faiz, vergi ve diğer giderler ile ilgili nakit akışlarının gelecekteki durumu hakkında daha açıklayıcı bilgiler sağlayabilmektedir (Krishnan ve Largay, 2000; Cheng veHollie, 2008; Orpurt veZang, 2009; Habib, 2010; Arthur vd., 2010; Bradbury, 2011; Bond vd., 2012; Farshadfarve Monem, 2013; Sun vd., 2018).

Nurnberg (1993) ve Krishnan and Largay (2000) tarafindan yapılan çalışmalarda, finansal kurumların kredi analiz işlemlerinde ve yatırımcıların karar alma süreçlerinde detaylı bilgiler içermesinden dolayı, doğrudan yönteme göre hazırlanmış nakit akış tablolarını tercih ettikleri ve doğrudan yöntemin kullanımını arttırmak amacıyla lobi faaliyeti yürüttükleri belirlenmiştir.

Broome (2004); CFA Institute (2009); Hales ve Orpurt (2013) ve Abu-Abbas, (2014) tarafindan yapılan çalışmada doğrudan yöntemin kullanıcılara sağladığı sekiz adet avantaj tespit edilmiştir. Bunlar sırasıyla (1) kolay anlaşılabilir nakit akış bilgileri sağlar, (2) nakit akış verilerinin daha kolay analizi ve tahmin modellerine yardımc1 olur, (3) detaylı ödeme gücü göstergeleri verir, (4) kabul gören ticari uygulamalara paralel bir yapı oluşturur, (5) ilgili taraflara daha kullanışlı finansal bilgiler sağlar, (6) gelecekteki nakit akışlarının doğru tahmini, (7) kâr analizlerinin daha detaylı yapılmasını sağlamaktır ve (8) nakit akışı, nakit akışı raporunun içerisine bağlanabileceği için varyans analizinde faydalıdır.

Doğrudan yöntem için ileri sürülen en önemli eleştiri yöntemin uygulanmasının maliyetli, zor ve karmaşık olmasıdır. Fakat Golub ve Huffman (1984) tarafindan yapılan araştırmada, doğrudan yöntemin dolaylı yönteme göre daha maliyetli bir yöntem olduğuna dair bir bulguya rastlanamamıştır. Ayrıca daha çok nakit akış verisi içeren ve ilk görüşte daha zor ve karmaşık görülen doğrudan yöntemle ilgili önyargının, yöntem kullanılmaya başladıktan sonra ortadan kalktığı belirlenmiştir.

Krishnan ve Largay (2000) veAbu-Abbas (2014) tarafindan yapılan çalışmalarda dolaylı yöntemin kullanıcılara sağladığı dört adet avantaj tespit edilmiştir. Bunlar sırasıyla (1) hazırlanmasının kolay olması, (2) daha anlamlı ve yalın bilgiler sağlaması, (3) kullanıcıların analiz yapmalarının daha kolay olması ve (4) uygulama maliyetinin daha az olmasi.

Doğrudan yöntemin sağladığı birçok avantaj bulunmasına rağmen, yapılan birçok uygulama çalışmasında dolaylı yöntemin uygulanma oranının yüzde seksenlerde olduğu tespit edilmiştir. Yine bu çalısmalarda, dolaylı yöntemin bu kadar yaygın kullanılmasının sebebi olarak iki faktörün ön plana çıktı̆̆ı görülmektedir. Bunlardan birincisi yöntemin uygulanmasının kolay olması, ikincisi ise işletmelerin hassas nakit akış verilerini detaylı olarak kamuoyu ile paylaşmak istememeleridir (Rue ve Kirk 1996; Krishnan and Largay, 2000; Clinch vd., 2002; Orpurt ve Zang, 2009; Özdemir, 2014). 


\section{Doğrudan ve Dolaylı Yönteme Göre Nakit Akış Tablosu Uygulaması}

Uygulama çalışmasının birinci aşamasında BOBİ FRS'de belirtilen finansal tablo şablonları kullanılarak oluşturulan X örnek işletmesinin "Finansal Durum Tablosu" ve Kâr ve Zarar Tablosu düzenlenmiştir (BOBİ FRS, s. 96-202). Tablolar aşağıda belirtilen şartlar dikkate alınarak hazırlanmışır:

Bir işletmenin 2018 yllı için büyük veya orta boy işletme sayılabilmesi ve BOBİ FRS'ye tabi olabilmesi için aşağıdaki üç ölçütten en az ikisinin eşik değerlerini, varsa bağlı ortaklıklarıyla birlikte, art arda iki raporlama döneminde aşması gerekmektedir (BOBİ FRS Hakkındaki Tebliğ, 2017):

a) Aktif toplamı 75 milyon ve üstü Türk Lirası.

b) Yıllık net satış hasılatı 150 milyon ve üstü Türk Lirası.

c) Ortalama çalışan sayısı 250 ve üstü.

$\mathrm{X}$ işletmesi mal ticareti yapan, son iki yıl ortalama 300 çalş̧anı bulunan bir anonim şirkettir. X A.Ş. ait Finansal Durum Tablosu Tablo 1'de ve Kâr ve Zarar Tablosu ise Tablo 2'de örneklendirilmiştir.

Uygulama çalışmasının ikinci aşamasında ise, BOBİ FRS'de belirtilen finansal tablo şablonları kullanılarak örnek X işletmesinin cari döneme ait "Nakit Akış Tablosu" "Doğrudan" ve Dolaylı" yönteme göre ayrı ayrı hazırlanmıştır. Kullanılan finansal verilerin içeriği "Dip Not" bölümünde açılanmıştır.

Doğrudan yöntem kullanılarak hazırlanan nakit akış tablosu Tablo 3'de, dolaylı yöntem kullanılarak hazırlanan nakit akış tablosu ise Tablo 4'de sunulmuştur.

Tablo 1. X Issletmesinin Finansal Durum Tablosu

X ANONIM ŞİRKETININ ......TARIHLII BAĞIMSIZ DENETIMDEN GEÇMIŞ

FINANSAL DURUM

\begin{tabular}{|c|c|c|c|}
\hline 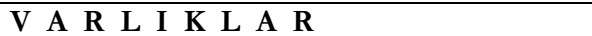 & Dip Not & Cari Dönem & Önceki Dönem \\
\hline DÖNEN VARLIKLAR & & 98.982 .099 & 72.204 .126 \\
\hline Nakit ve Nakit Benzerleri & & 34.257 .479 & 10.704 .214 \\
\hline Finansal Yatırımlar & & 0 & 0 \\
\hline Ticari Alacaklar & 2 & 26.597 .336 & 27.995 .208 \\
\hline Diğer Alacaklar & & 0 & 0 \\
\hline Devam Eden İnșa Sözleșmelerinden Alacaklar & & 0 & 0 \\
\hline Stoklar & 6 & 28.911 .869 & 23.025 .778 \\
\hline Canlı Varliklar & & 0 & 0 \\
\hline Peşin Ödenmiş Giderler & & 0 & 0 \\
\hline Peșin Ödenmiș Vergi ve Benzerleri & 14 & 9.215 .415 & 10.478 .926 \\
\hline Diğger Dönen Varlıklar & & 0 & 0 \\
\hline DURAN VARLIKLAR & & 18.340 .242 & 16.583.224 \\
\hline Ticari Alacaklar & & 0 & 0 \\
\hline Diğer Alacaklar & & 0 & 0 \\
\hline Devam Eden İnşa Sözleşmelerinden Alacaklar & & 0 & 0 \\
\hline Finansal Yatırımlar & & 0 & 0 \\
\hline Özkaynak Yöntemiyle Değerlenen Yatırımlar & & 0 & 0 \\
\hline Canlı Varlıklar & & 0 & 0 \\
\hline Yatırım Amaçlı Gayrimenkuller & & 0 & 0 \\
\hline Maddi Duran Varlıklar & 16 & 9.124 .827 & 8.324 .710 \\
\hline Maddi Olmayan Duran Varlıklar & 17 & 9.215 .415 & 8.258 .514 \\
\hline Peşin Ödenmiş Giderler & & 0 & 0 \\
\hline Ertelenmiș Vergi Varlığ1 & & 0 & 0 \\
\hline Diğer Duran Varlıklar & & 0 & 0 \\
\hline TOPLAM VARLIKLAR & & 117.322.341 & 88.787 .350 \\
\hline K A Y N A K L A R & Dip Not & Cari Dönem & Önceki Dönem \\
\hline KISA VADELİ YÜKÜMLÜLÜKLER & & 35.697 .020 & 40.527 .535 \\
\hline Finansal Yükümlülükler & 19 & 12.365 .748 & 13.415 .874 \\
\hline Ticari Borçlar & 7 & 22.456 .058 & 26.597 .336 \\
\hline Diğger Borçlar & & 0 & 0 \\
\hline Devam Eden İnşa Sözleşmelerinden Borçlar & & 0 & 0 \\
\hline Alınan Avanslar & 3 & 875.214 & 514.325 \\
\hline Ödenecek Vergi ve Benzeri Yükümlülükler & & 0 & 0 \\
\hline Kısa Vadeli Karşılıklar & & & \\
\hline
\end{tabular}


ÖZDEMİR

Büyük ve Orta Boy Işsletmeler İçin Finansal Raporlama Standardı (BOBİ FRS) Kapsamında Nakit Akış Tablosu Düzenlenmesinde Doğrudan - Dolaylı Yöntem Tartışması ve Karşılaştırmalı Örnek Bir Uygulama

\begin{tabular}{|c|c|c|c|}
\hline -Vergi Karşlıkları & & 0 & 0 \\
\hline -Borç Karşlıkları & & 0 & 0 \\
\hline Ertelenmiş Gelirler & & 0 & 0 \\
\hline Diğer Kısa Vadeli Yükümlülükler & & 0 & 0 \\
\hline UZUN VADELİ YÜKÜMLÜLÜKLER & & 2.423 .124 & 1.782 .003 \\
\hline Finansal Yükümlülükler & & 0 & 0 \\
\hline Ticari Borçlar & & 0 & 0 \\
\hline Diğger Borçlar & & 0 & 0 \\
\hline Devam Eden İnşa Sözleşmelerinden Borçlar & & 0 & 0 \\
\hline Alınan Avanslar & & 0 & 0 \\
\hline Ödenecek Vergi ve Benzeri Yükümlülükler & & 0 & 0 \\
\hline \multicolumn{4}{|l|}{ Uzun Vadeli Karş1lıklar } \\
\hline -Kıdem Tazminatı Karşı1ıkları & 12 & 2.423 .124 & 1.782 .003 \\
\hline Ertelenmiş Gelirler & & 0 & 0 \\
\hline Ertelenmiş Vergi Yükümlülüğü & & 0 & 0 \\
\hline Diğer Uzun Vadeli Yükümlülükler & & 0 & 0 \\
\hline Ö Z K A Y N A K L A R & & 79.202 .197 & 46.477 .812 \\
\hline Ödenmiş Sermaye & 18 & 39.982 .334 & 9.612 .059 \\
\hline Geri Alınmış Paylar (-) & & 0 & 0 \\
\hline Paylara İlişkin Primler & 21 & 0 & 12.866 .410 \\
\hline Yeniden Değerleme Yedeği & & 0 & 0 \\
\hline Yabancı Para Çevrim Farkları & & 0 & 0 \\
\hline Koruma Yedeği & & 0 & 0 \\
\hline \multicolumn{4}{|l|}{ Kâr Yedekleri } \\
\hline -Yasal Yedekler & & 9.024 .015 & 0 \\
\hline -Statü Yedekleri & & 8.288 .561 & 0 \\
\hline Geçmiş Yıllar Kârları/Zararları & 20 & 3.478 .645 & 6.314 .215 \\
\hline Dönem Net Kâr1/Zarar1 & & 18.428 .642 & 17.685 .128 \\
\hline TOPLAM KAYNAKLAR & & 117.322.341 & 88.787 .350 \\
\hline
\end{tabular}

Tablo 2. X İsletmesinin Kâr ve Zarar Tablosu

X ANONIM ŞIRKETININ ......DÖNEMINE AİT BAĞIMSIZ DENETIMDEN GEÇMIŞ KÂR VE ZARAR TABLOSU (TL)

\begin{tabular}{|c|c|c|c|}
\hline & Dip Not & Cari Dönem & Önceki Dönem \\
\hline Satış Hasılatı & 1 & 160.673 .964 & 174.812 .362 \\
\hline Satışların Maliyeti (-) & 5 & -120.364 .412 & -132.514 .874 \\
\hline Brüt Kâr (Zarar) & & 40.309 .552 & 42.297 .488 \\
\hline Araştırma ve Geliştirme Giderleri (-) & 9 & -341.547 & 589.645 \\
\hline Pazarlama Giderleri (-) & 9 & -13.465 .796 & -15.478 .625 \\
\hline Genel Yönetim Giderleri (-) & 9 & -7.512 .489 & -9.412 .857 \\
\hline Esas Faaliyetlerden Diğer Gelirleri & 4 & 1.538 .644 & 1.912 .578 \\
\hline Esas Faaliyetlerden Diğer Giderler (-) & 11 & -1.974 .856 & -2.587 .956 \\
\hline Esas Faaliyet Kârı/Zararı & & 18.553 .508 & 17.320 .273 \\
\hline Diğer Faaliyetlerden Gelirler & 22 & 814.954 & 982.142 \\
\hline Diğer Faaliyetlerden Giderler (-) & 23 & -564.745 & -645.897 \\
\hline Finansal Gelirler & $10-15$ & 8.564 .315 & 9.524 .789 \\
\hline Finansal Giderler (-) & $12-13$ & -4.332 .229 & -5.217 .632 \\
\hline Dönem Kârı veya Zararı & & 23.035 .803 & 21.963 .675 \\
\hline Vergi Gideri (-) & & -4.607 .161 & -4.278 .547 \\
\hline Dönem Net Kârı veya Zararı & & 18.428 .642 & 17.685.128 \\
\hline
\end{tabular}


Tablo 3. X İsletmesinin Doğrudan Yönteme Göre Hažrlanmış Nakit Akış Tablosu

X ANONIM ŞiRKETININ ......DÖNEMINE AITT BAĞIMSIZ DENETIMDEN GEÇMIŞ NAKIT AKIŞ TABLOSU (TL)

\begin{tabular}{|c|c|c|c|c|}
\hline A) ESAS FAALİYETLERDEN NAKİT AKIŞLARI & $\begin{array}{l}\text { Dip } \\
\text { Not }\end{array}$ & \multicolumn{2}{|c|}{$(1+2+3+4+5)$} & 8.372 .961 \\
\hline 1. Esas Faaliyetlerden Net Nakit Akışları & & & & 19.905 .521 \\
\hline a) Nakit Girişi $(+)$ & & & 163.971 .369 & \\
\hline Mal Satışlarından Nakit Girişleri (+) & 1 & 160.673 .964 & & \\
\hline Ticari Alacaklardaki Artışlar (Satışlardan kayn.) (-) & & 0 & & \\
\hline Ticari Alacaklardaki Azalışlar (Satışlardan kayn.)(+) & 2 & 1.397 .872 & & \\
\hline Alınan Sipariş Avanslarındaki Artışlar (+) & 3 & 360.889 & & \\
\hline Alınan Sipariş Avanslarındaki Azalışlar (-) & & 0 & & \\
\hline Esas Faaliyetlerden Diğer Nakit Girişleri $(+)$ & 4 & 1.538 .644 & & \\
\hline b) Nakit Ç1kış1 (-) & & & -144.065 .848 & \\
\hline Satılan Mal Maliyetine İlişkin Nakit Çıkışları (-) & 5 & -120.364 .412 & & \\
\hline Araștırma ve Geliștirme Giderleri (-) & 9 & -341.547 & & \\
\hline Pazarlama, Satış ve Dağıtım Giderleri (-) & 9 & -13.465 .796 & & \\
\hline Genel Yönetim Giderleri (-) & 9 & -7.512 .489 & & \\
\hline Stoklardaki Artışlar (-) & 6 & -5.886 .091 & & \\
\hline Stoklardaki Azalışlar $(+)$ & & 0 & & \\
\hline Ticari Borçlardaki Azalışlar (-) & & 0 & & \\
\hline Ticari Borçlardaki Artışlar $(+)$ & 7 & 4.098 .591 & & \\
\hline Esas Faaliyetlerden Diğer Giderler (-) & 11 & -1.974 .856 & & \\
\hline Amortisman ve Nakit Çıkışı Gerektirmeyen Giderler $(+)$ & 8 & 1.380 .752 & & \\
\hline 2. Ödenen Faizler (-) & 13 & & & -3.562 .415 \\
\hline 3. Ödenen Geçici Vergiler (-) & 14 & & & -9.215 .415 \\
\hline 4. Diğer Nakit Girişleri (+) & & & & 399.080 \\
\hline a) Nakit Çıkışını Gerektirmeyen Diğ. Gel. ve Kâr. (-) & 10 & & -415.874 & \\
\hline b) Diğer Nakit Girişleri $(+)$ & 22 & & 814.954 & \\
\hline 5. Diğer Nakit Çıkışları (-) & & & & 846.190 \\
\hline a) Nakit Çıkışını Gerektirmeyen Diğ. Gid.ve Zar. $(+)$ & 12 & & 1.410 .935 & \\
\hline b) Diğer Nakit Çıkışları (-) & 23 & & -564.745 & \\
\hline B) YATIRIM FAALIYYTLERİNDEN NAKİT AKIŞLARI & & & & 6.199 .590 \\
\hline 1. Yatırım Faal. Sağlanan Nakit Girişleri $(+)$ & & & & 8.148 .441 \\
\hline a) Mali Duran Varlık Sat.Sağ.Nakit Girişleri (+) & & & 0 & \\
\hline b) Maddi Duran Varlık Sat. Sağ.Nakit Girişleri (+) & & & 0 & \\
\hline c) Diğer Duran Varlık Sat. Sağ.Nakit Girişleri (+) & & & 0 & \\
\hline c) Mali Dur. Varlık. İlgili Al. Tem. Sağ.Nak. Gir.(+) & & & 0 & \\
\hline d) Yatırım Faal. İle İlg. Faiz. Sağ. Nak. Giriş.(+) & 15 & & 8.148 .441 & \\
\hline e) Devlet Teşviklerinden Nakit Girişleri (+) & & & 0 & \\
\hline f) Verilen Nakit Avans ve Borç. Geri Ödemeler (+) & & & 0 & \\
\hline g) Diğer Uzun Vadeli Varlık Satış. Nakit Giriș. (+) & & & 0 & \\
\hline h) Diğer Yatırım Faaliyetlerinden Nakit Girişleri $(+)$ & & & 0 & \\
\hline 2. Yatırım Faal. İlişskin Nakit Çıkışları (-) & & & & -1.948 .851 \\
\hline a) Mali Duran Varlık Artışları (-) & & & 0 & \\
\hline b) Maddi Duran Varlık Artışları (-) & 16 & & -951.223 & \\
\hline c) Maddi Olmayan Duran Varlık Artışları (-) & 17 & & -997.628 & \\
\hline ç) Özel Tükenmeye Tabi Varlıklardaki Artışlar (-) & & & 0 & \\
\hline d) Diğer Duran Varlık Artışları (-) & & & 0 & \\
\hline e) Verilen Nakit Avans ve Borçlar (-) & & & 0 & \\
\hline f) Diğer Uzun Vadeli Varlık Alım. Nakit Cııkıs. (-) & & & 0 & \\
\hline g) Diğer Yatırım Faaliyetlerine İlişkin Nakit Çık. (-) & & & 0 & \\
\hline C) FİNANSMAN FAAL. NAKİT AKISLARI & & & & 8.980 .714 \\
\hline 1. Finansman Faal. Sağlanan Nakit Girişleri $(+)$ & & & & 30.370 .275 \\
\hline a) Kısa Vadeli Borçlanmalardan Sağlanan Nakit (+) & & & 0 & \\
\hline b) Uzun Vadeli Borçlanmalardan Sağlanan Nakit (+) & & & 0 & \\
\hline c) Sermaye Artırımından Sağlanan Nakit (+) & 18 & & 30.370 .275 & \\
\hline d) Hisse Senedi İhraç Primlerinden Sağl. Nakit (+) & & & 0 & \\
\hline e) Diğer Finansman Faal. Sağ. Nakit Giriș. $(+)$ & & & 0 & \\
\hline 2. Finansman Faal. İlişkin Nakit Çıkışları (-) & & & & -21.389 .561 \\
\hline a) Kısa Vadeli Borç Ödemeleri (-) & 19 & & -1.050 .126 & \\
\hline b) Uzun Vadeli Borç Ödemeleri (-) & & & 0 & \\
\hline c) Ödenen Temettüler (-) & 20 & & -2.835 .570 & \\
\hline
\end{tabular}


ÖZDEMİR

Büyük ve Orta Boy Işsletmeler İçin Finansal Raporlama Standardı (BOBİ FRS) Kapsamında Nakit Akış Tablosu

Düzenlenmesinde Doğrudan - Dolaylı Yöntem Tartışması ve Karşılaştırmalı Örnek Bir Uygulama

d) Sermaye Azaltılması (-)

e) Diğer Finansman Faal. İlişskin Nakit Çıkış. (-)

D) KUR FARKLARININ NAKİT VE NAKİT

BENZERLERINE ETKILERİ (+), (-)

E) NAKİT VE NAKİT BENZERLERİNDE OLUŞAN NET

ARTIŞ (+), AZALIŞ (-)

F) DÖNEMBAŞI NAKİT VE NAKİT BENZERLERİ

MEVCUDU

G) DÖNEM SONU NAKİT VE NAKİT BENZERLERİ

MEVCUDU

\begin{tabular}{|l|r|r|r|} 
& & 0 & \\
\hline & 21 & -17.503 .865 & \\
\hline $\mathbf{T}$ & & & 0 \\
\hline & $\begin{array}{c}\text { (Geçmiş Dönem Sonu Nakit } \\
\text { ve Nakit Benz. Mevcudu) }\end{array}$ & $\mathbf{1 0 . 7 0 4 . 2 1 4}$ \\
\hline & $(\mathbf{E}+\mathbf{F})$ & $\mathbf{3 4 . 2 5 7 . 4 7 9}$ \\
\hline
\end{tabular}

Tablo 4. X İsletmesinin Dolaylı Yönteme Göre Hą̦ırlanmış Nakit Akıs Tablosu

X ANONIM ŞİRKETININ ......DÖNEMINE AİT BAĞIMSIZ DENETIMDEN GEÇMIŞ NAKİT AKISS TABLOSU (TL)

\begin{tabular}{|c|c|c|c|c|}
\hline A) ESAS FAALIYYETLERDEN NAKİT AKIŞLARI & \begin{tabular}{l|} 
Dip \\
Not
\end{tabular} & \multicolumn{2}{|c|}{$(1+2+3+4+5)$} & 8.372 .991 \\
\hline 1. Esas Faaliyetlerden Net Nakit Akışları & & & & 19.905.551 \\
\hline a) Dönem Net Kâr1/Zararı & & & 18.428 .642 & \\
\hline b) Düzeltmeler & & & 726.392 & \\
\hline Amortisman ve İtfa Gideri $(+)$ & 8 & 1.380 .742 & & \\
\hline Maddi Duran Var. Değer düşüklüğü/değer düş. İpt.(+)/(-) & & 0 & & \\
\hline Maddi Olmayan Duran Var. Değer düş./değ.düş. ipt. $(+) /(-)$ & & 0 & & \\
\hline Sat.Amaç.Eld.Tut. Duran Var. Değ. düş./değ. düş.İpt. $(+) /(-)$ & & 0 & & \\
\hline Karşılıklarla/konusu kalmayan karşılıklar ilgili düz. $(+) /(-)$ & & 0 & & \\
\hline Faiz gelirleri/giderleriyle ilgili düzeltmeler $(-) /(+)$ & & 0 & & \\
\hline Gerçekleşmemiş olumsuz/olumlu kur fark. ilgili düzelt. (+)/(-) & & 0 & & \\
\hline Gerçeğe uygun değer kayıpları/kazançları ile ilg. düzelt.(-)/(+) & & 0 & & \\
\hline Nakit dışı kalemlere ilişkin diğer düzeltmeler & & 0 & & \\
\hline Duran varl. elden çıkarılmasından kayıp/kazanç. ile ilg. düzelt. & & 0 & & \\
\hline $\begin{array}{l}\text { Yatırım ya da finansman faal. nakit akış. neden olan diğer kalem. ilişkin } \\
\text { düzeltmeler }\end{array}$ & & 0 & & \\
\hline Vergi Gelir/Giderleri ilgili diğer düzeltmeler & & 0 & & \\
\hline Kâr/zarar mutabakatı ile ilgili diğer düzeltmeler & 24 & -654.350 & & \\
\hline b) Değişimler & & & 750.517 & \\
\hline Stoklardaki artış/azalış $(+) /(-)$ & 6 & 5.886 .091 & & \\
\hline Ticari alacaklardaki artış/azalış $(+) /(-)$ & 2 & -1.397 .872 & & \\
\hline Faaliyetlerle ilgili diğer alacaklardaki artış/azalış $(+) /(-)$ & & 0 & & \\
\hline Ticari borçlardaki artı̧/azalış $(-) /(+)$ & 7 & -4.098 .591 & & \\
\hline Faaliyetlerle ilgili diğer borçlardaki artış/azalış $(-) /(+)$ & & & & \\
\hline Alınan sipariş avanslarında artış/azalış $(+) /(-)$ & 3 & 360.889 & & \\
\hline 2. Ödenen Faizler (-) & 13 & & & -3.562 .415 \\
\hline 3. Ödenen Geçici Vergiler (-) & 14 & & & -9.215 .415 \\
\hline 4. Diğer Nakit Girişleri (+) & & & & 399.080 \\
\hline a) Nakit Çıkışını Gerektirmeyen Diğer Gelir ve Kâr. (-) & 10 & & -415.874 & \\
\hline b) Diğer Nakit Girişleri (+) & 22 & & 814.954 & \\
\hline 5. Diğer Nakit Çıkışları (-) & & & & 846.190 \\
\hline a) Nakit Çıkışını Gerektirmeyen Diğer Gider ve Zar. $(+)$ & 12 & & 1.410 .935 & \\
\hline b) Diğer Nakit Çıkışları (-) & 23 & & -564.745 & \\
\hline B) YATIRIM FAALIYYTLERİNDEN NAKİT AKIŞLARI & & $(1+$ & & 6.199 .560 \\
\hline 1. Yatırım Faal. Sağlanan Nakit Girişleri (+) & & & & 8.148 .411 \\
\hline a) Mali Duran Varlık Sat.Sağ.Nakit Girişleri (+) & & & 0 & \\
\hline b) Maddi Duran Varlık Sat. Sağ.Nakit Girişleri (+) & & & 0 & \\
\hline c) Diğer Duran Varlık Sat. Sağ.Nakit Girişleri (+) & & & 0 & \\
\hline ç) Mali Dur. Varlıklarla İlgili Al. Tem. Sağ. Nak. Gir.(+) & & & 0 & \\
\hline d) Yatırım Faal. İle İlgili Faizlerden Sağ. Nakit Gir. (+) & 15 & & 8.148 .411 & \\
\hline e) Devlet Teşviklerinden Nakit Girişleri (+) & & & 0 & \\
\hline f) Verilen Nakit Avans ve Borçlardan Geri Öd. (+) & & & 0 & \\
\hline g) Diğer Uzun Vadeli Varlık Satışlarından Nakit Gir. (+) & & & 0 & \\
\hline h) Diğer Yatırım Faaliyetlerinden Nakit Girişleri (+) & & & 0 & \\
\hline 2. Yatırım Faal. İlişkin Nakit Çıkışları (-) & & & & -1.948 .851 \\
\hline a) Mali Duran Varlık Artışları (-) & & & 0 & \\
\hline b) Maddi Duran Varlık Artışları (-) & 16 & & -951.223 & \\
\hline c) Maddi Olmayan Duran Varlık Artışları (-) & 17 & & -997.628 & \\
\hline ç) Özel Tükenmeye Tabi Varlıklardaki Artışlar (-) & & & 0 & \\
\hline
\end{tabular}




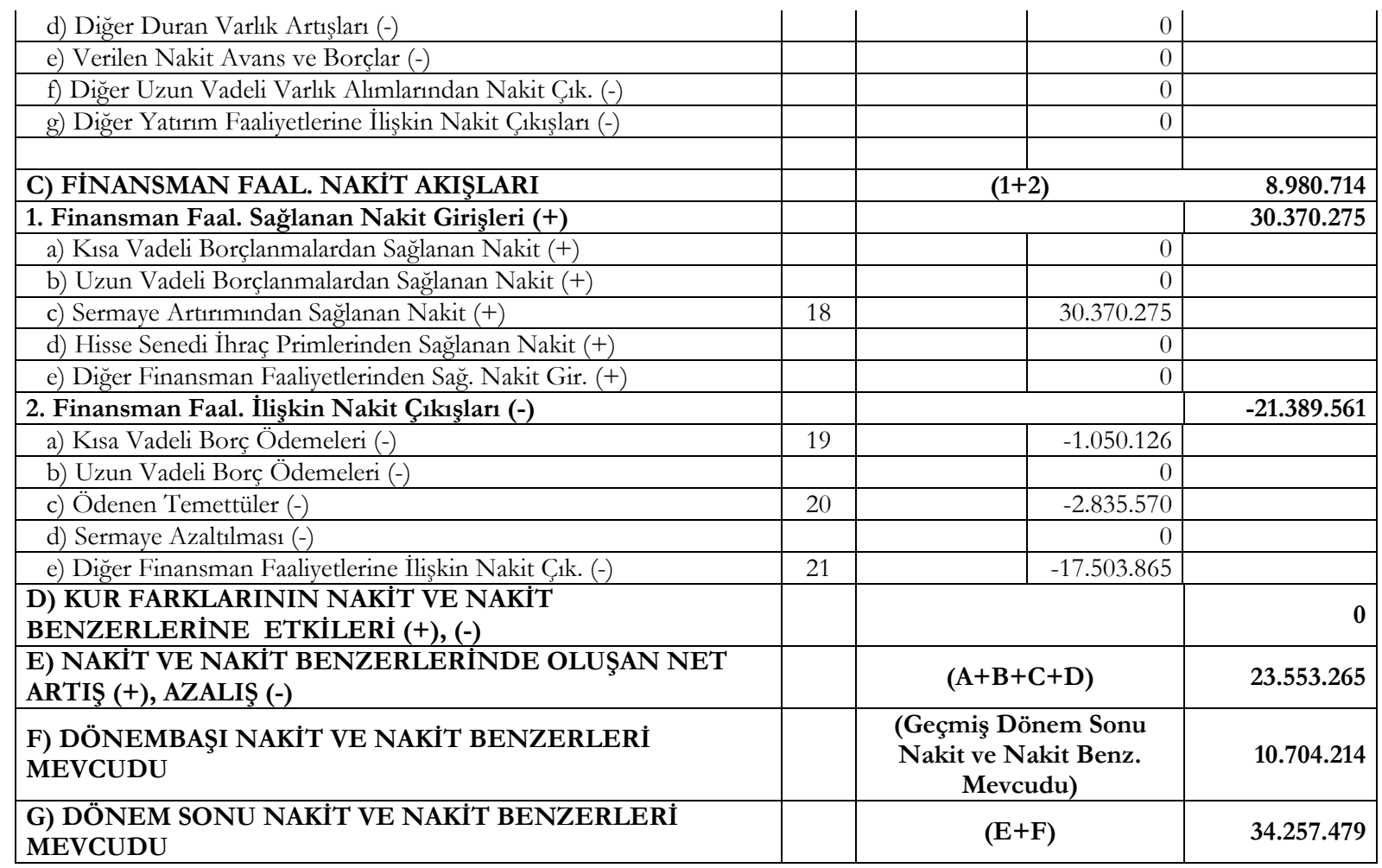

Dip Not 1: Kâr ve Zarar Tablosu

\begin{tabular}{lr} 
& Cari Dönem \\
\cline { 2 - 2 } Yurtiçi Satışlar & $144.625 .520 .-$ \\
Yurtdış Satışlar & $34.034 .261 .-$ \\
Diğer Gelirler & $940.560 .-$ \\
Satı̧lardan İadeler (-) & $(11.412 .108 .-)$ \\
Satıs İskontoları (-) & $(7.514 .269 .-)$ \\
Mal Satış1. Nakit Girişleri & $\mathbf{1 6 0 . 6 7 3 . 9 6 4 . -}$
\end{tabular}

Dip Not 2: Finansal Durum Tablosu

\begin{tabular}{|c|c|c|}
\hline Ticari Alacaklar & Cari Dönem & Önceki Dönem \\
\hline Alıcilar & 18.125.406.- & 20.814.122.- \\
\hline Alacak Senetleri & 9.241.744.- & 8.122.411.- \\
\hline Alacak Sen. Reesk. (-) & (769.814.-) & (Dip Not 12)(941.325).- \\
\hline TOPLAM & 26.597.336.- & 27.995.208.- \\
\hline Ticari Alacaklardaki Azalı & $\begin{array}{l}=26.597 .336-27.995 .208 \\
=-1.397 .872 .-\end{array}$ & \\
\hline
\end{tabular}

Dip Not 3: Finansal Durum Tablosu

Cari Dönem

Önceki Dönem

Alinan Avansları 875.214.

514.325.-

Alınan Sipariş Avanslarındaki Artışlar= $875.214-514.325$

$$
=360.889
$$

Dip Not 4: Kâr ve Zarar Tablosu

Esas Faaliyetlerden Diğer Gelirleri

Esas Faaliyetlerden Diğer Nakit Girişleri

\section{Cari Dönem}

$$
\text { 1.538.644.- }
$$

Dip Not 5: Kâr ve Zarar Tablosu

Satışların Maliyeti (-)

$$
\text { Cari Dönem }
$$

Satılan Mal Maliyetine İlişkin Nakit Çıkışları

$$
\text { (120.364.412.-) }
$$

Dip Not 6: Finansal Durum Tablosu

Ticari Mallar

Diğer Stoklar

\section{Cari Dönem}

28.011.414.-

900.455.-

\section{Önceki Dönem}

22.570.312.-

455.466.- 
ÖZDEMİR

Büyük ve Orta Boy İşletmeler İçin Finansal Raporlama Standardı (BOBİ FRS) Kapsamında Nakit Akış Tablosu Düzenlenmesinde Doğrudan - Dolaylı Yöntem Tartışması ve Karşılaştırmalı Örnek Bir Uygulama

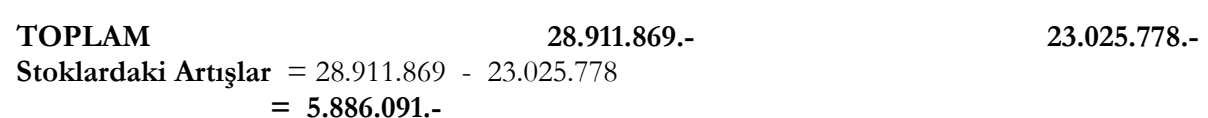

Dip Not 7: Finansal Durum Tablosu

\begin{tabular}{lcrr} 
& \multicolumn{2}{c}{ Cari Dönem } & \multicolumn{2}{c}{ Önceki Dönem } \\
\cline { 2 - 4 } Satıclar & $17.254 .109 .-$ & $14.526 .847 .-$ \\
Borç Senetleri & $5.617 .823 .-$ & $4.214 .874 .-$ \\
Borç Senetleri Reeskontu (-) & $(415.874 .-)($ Dip Not 10) & $(384.254 .-)$ & \\
TOPLAM & $\mathbf{2 2 . 4 5 6 . 0 5 8 . -}$ & & 18.357.467.-
\end{tabular}

Ticari Borçlardaki Artışlar $=22.456 .058-18.357 .467$

$$
=4.098 .591 \text {.- }
$$

Dip Not 8: Hesaplanan Amortisman ve İtfa Giderleri

Maddi Duran Varlıklar

Taşıt Amortismanı

Maddi Olmayan Duran Varlıklar

Serefiye Ittfası

TOPLAM

Cari Dönem

965.427.-

Amortisman ve Nakit Çık. Gerektirmeyen Gid. $=$ 1.380.752.-

Dip Not 9: Kâr ve Zarar Tablosu

Araştırma ve Geliştirme Giderleri(-)

Pazarlama, Satış ve Dağıtım Giderleri(-)

Genel Yönetim Giderleri(-)

\section{Cari Dönem}

$(13.465 .796 .-)$

(7.512.489.-)

Dip Not 10: Kâr ve Zarar Tablosu

Finansal Gelirler

Cari Dönem

Reeskont Faiz Gelirleri 415.874.-

Nakit Çıkı̧ııı Gerektirmeyen Diğer Gelir ve Kârlar (-)

Dip Not 11: Kâr ve Zarar Tablosu

Esas Faaliyetlerden Diğer Giderler (-)

\section{Cari Dönem}

$(1.974 .856 .-)$

Esas Faaliyetlerden Diğer Giderler (-)

Dip Not 12: Kâr ve Zarar Tablosu

\begin{tabular}{lr}
\hline Finansal Giderler (-) & Cari Dönem \\
Reeskont Faiz Giderleri (-) & $(769.814 .-)$ \\
Kıdem Tazminatı Karşlık Giderleri (-) & $(\underline{641.121 .-)}$ \\
TOPLAM & $\mathbf{( 1 . 4 1 0 . 9 3 5 . - )}$
\end{tabular}

Nakit Çıkışını Gerektirmeyen Diğer Gider ve Zararlar (+)

Dip Not 13: Kâr ve Zarar Tablosu

Finansal Giderler (-)

Faiz Giderleri (-)

Cari Dönem

Ödenen Faizler (-)

Dip Not 14: Finansal Durum Tablosu

Peşin Ödenmiş Vergi ve Benzerleri

\section{Cari Dönem}

Ödenen Geçici Vergiler

Dip Not 15: Kâr ve Zarar Tablosu

\section{Finansal Gelirler}

Faiz Gelirleri

Yatırım Faaliyetleri İle İlgili Faizlerden Sağlanan Nakit Girişleri

Dip Not 16: Finansal Durum Tablosu

Taşıtlar

Hesaplanan Amortisman

TOPLAM

Maddi Duran Varlık Artışları

$$
\begin{aligned}
& \text { Cari Dönem } \\
& \text { 9.124.827. } \\
& \text { 965.427.-(Dip Not 8) } \\
& \text { 10.090.254.- } \\
& =10.090 .254-9.139 .031 \\
& \text { = 951.223.- }
\end{aligned}
$$

Dip Not 17: Finansal Durum Tablosu

$\frac{\text { Cari Dönem }}{9.215 .415 .-} \quad \frac{\text { Önceki Dönem }}{8.258 .514 .-}$




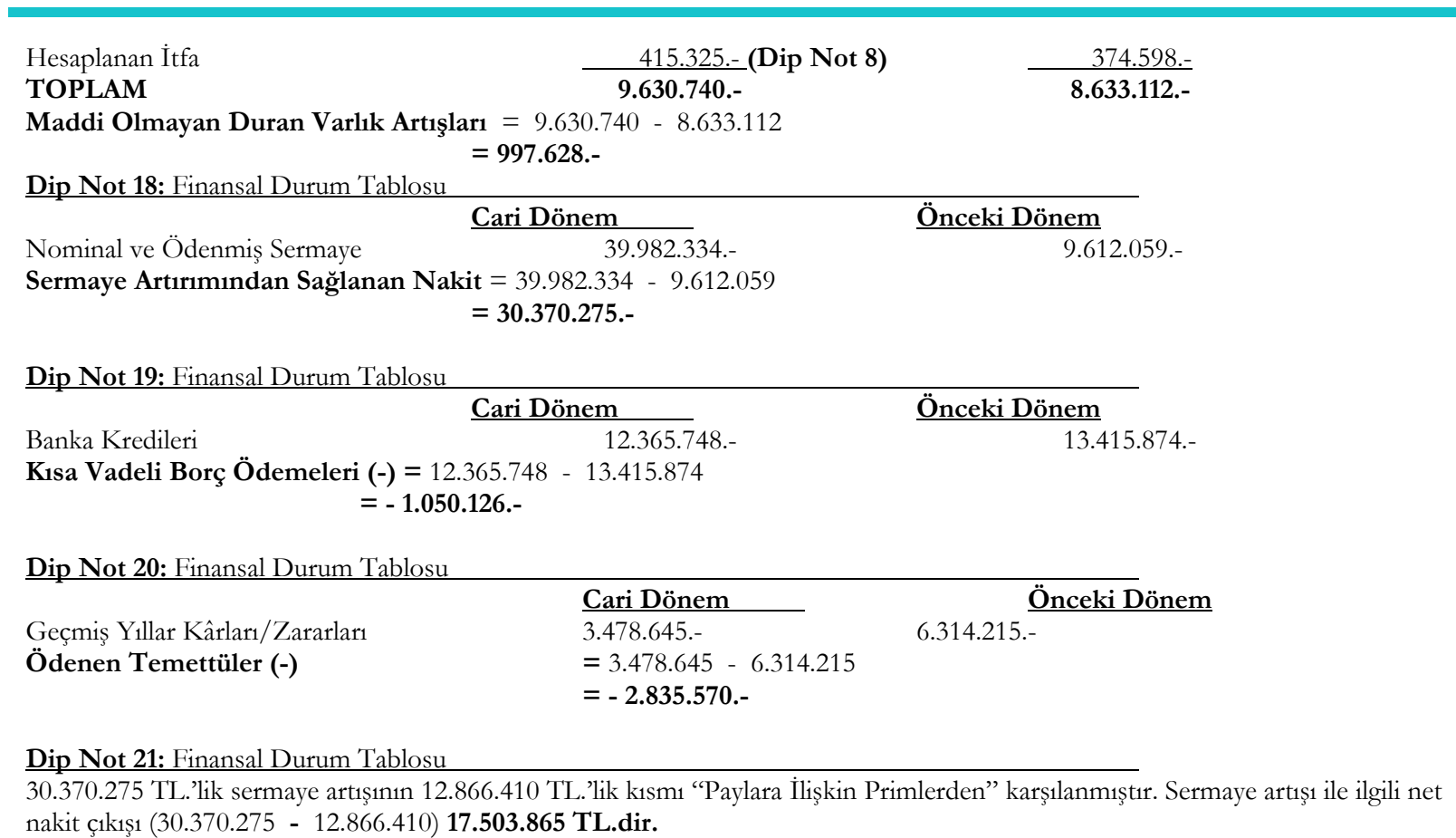
nakit çıkışı (30.370.275 - 12.866.410) 17.503.865 TL.dir.

Dip Not 22: Kâr ve Zarar Tablosu

Diğer Faaliyetlerden Gelirler $\quad \frac{\text { Cari Dönem }}{814.954 .-}$

Diğer Nakit Girişleri

Dip Not 23: Kâr ve Zarar Tablosu

$\begin{array}{lc}\text { Diğer Faaliyetlerden Giderler (-) } & \text { Cari Dönem } \\ \text { Diğer Nakit Çıkısları } & (564.746 .-)\end{array}$

Dip Not 24:

Doğrudan yöntem ile dolaylı yöntemin aynı örnek işletme üzerinden uygulanması sonucunda ortaya çıan hesaplanamayan farkların düzeltmesi ve dolaylı yöntem sonuçlarının denkleştirilmesi.

Tablo 3 ve 4 karşılaştırıldığında, doğrudan yöntemle hazırlanmış nakit akış tablosunun "Esas Faaliyetlerden Nakit Akışları" bölümünde, dolaylı yöntemle hazırlanmış nakit akış tablosuna göre daha detaylı finansal bilgilere yer verildiği görülmektedir. Her iki yöntemin "Yatırım Faaliyetlerinden Nakit Akışları" ve "Finansman Faaliyetlerinden Nakit Akışları" bölümlerinde, aynı finansal bilgilere yer verilmekte ve yöntemler arasında fark bulunmamaktadır.

\section{Sonuç ve Öneriler}

İşletmeler gelecek planları yapabilmek ve yönetim kararları alabilmek; şirket ortakları, yatırımcılar ve diğer üçüncü şahıslar ise işletme hakkında analizler yapabilmek için doğru ve detaylı finansal bilgiler içeren finansal tablolara ihtiyaç duyarlar. Nakit akış tablosu BOBI FRS ve TFRS tabi işletmelerin düzenlemek zorunda oldukları en önemli finansal tablolardan biridir. Nakit akım tablosu "Doğrudan" ve "Dolaylı" yöntemlerden biri kullanılarak düzenlenebilmektedir.

Türkiye'de BOBİ FRS 1 Ocak 2018 tarihinden itibaren belirtilen şartları sağlayan işletmeler tarafindan uygulanmaya başlamıştır. BOBİ FRS'de TFRS'nin aksine nakit akış tablolarının hangi yöntemle düzenleneceğine dair bir öneri bulunmamaktadır. Bu sebeple çalışmada, örnek X işletmesinin nakit akış tablosu, her iki yöntem kullanılarak düzenlenmiştir.

Literatürde nakit akım tablosunda doğrudan yöntemin kullanılmasının, ilişkili taraflar açısından daha faydalı olacağına dair birçok çalışma bulunmaktadır. Fakat buna rağmen anlaşılabilir sade yapısı, hazırlanmasının kolay olması ve işletmelerin kamuoyu ile fazla finansal bilgi paylaşmama istekleri gibi sebeplerle, dolaylı yöntemin daha yaygın olarak kullanıldı̆̆ı tespit edilmiştir. 
Uygulama çalışmasında doğrudan yöntemle hazırlanmış nakit akış tablosunun "Esas Faaliyetlerden Nakit Akışları" bölümünde, dolaylı yöntemle hazırlanmış nakit akış tablosuna göre daha detaylı finansal bilgilere yer verildiği görülmektedir. Ayrıca dolaylı yöntemle hazırlanan nakit akım tablosunun daha sade ve anlaşılır bir yapıya sahip olduğu görülmektedir. Bu durum, dolaylı yöntemin işletmeler tarafindan daha çok tercih edilmesine ait yukarıda belirtilen sebepleri desteklemektedir. Fakat her iki yöntemin "Yatırım Faaliyetlerinden Nakit Akışları" ve "Finansman Faaliyetlerinden Nakit Akışları" bölümlerinde, aynı finansal bilgilere yer verilmekte ve yöntemler arasında fark bulunmamaktadır.

Çalışmada BOBİ FRS’yi kullanacak işletmeler için nakit akım tablolarının düzenlemesi ve yöntemlerin getirdiği avantaj ve dezavantajlar karşılaştırmalı olarak ortaya konulmuş; bir uygulama rehberi oluşturulmaya çalışılmıştır.

\section{Kaynakça}

Abu-Abbas, B. M. (2014). Direct, indirect, or both methods of reporting operating statement of cash flows. International Journal of Finance and Accounting, 3(6), 335-340.

Arar, M. (2018). BOBİ FRS Muhasebesi, http://www.bobiturk.com/wp-content/uploads/bobi-frs-muhasebesi1.pdf, Erişim Tarihi: 16.01.2019.

Arthur, N., Cheng, M. ve Czernkowski, R. (2010). Cash flow disaggregation and the prediction of future earnings. Accounting and Finance, 50(1), 1-30.

Bond, D., Bugeva, M. ve Czernkowski, R. (2012). Did Australian firms choose to switch to reporting operating cash flows using the indirect method? Australian Accounting Review, 22(1), 18-24.

Bradbury, M. (2011). Direct or indirect cash flow statement. Australian Accounting Review, 21(2), 124-130.

Broome, O. W. (2004). Statement of cash flows: Time for a change! Financial Analysts Journal, 8, 16-22.

CFA Institute (2009). Comment letter on preliminary viens on FSP. (April 14.) Charlottesville, VA: CFA Institute.

Cheng, A. C. S. ve Hollie, D. (2008).Do core and noncore cash flows from operations persist differentially in predicting future cash flows. Review of Quantitative Finance and Accounting, 31, 29-53.

Clinch, G., Sidhu, B. ve Sin, S. (2002). The usefulness of direct and indirect cash flow disclosures. Revien of Accounting Studies, 7, 383-404.

Doğan, A. (2018). Büyük ve orta boy işletmeler için finansal raporlama standardı ile VUK/MSUGT karşılaştırması. Mubasebe ve Finansman Dergisi, 80, 115-132.

Farshadfar, S. ve Monem, R. (2013). The usefulness of operating cash flow and accrual components in improving the predictive ability of earnings: A re-examination and extension. Accounting \& Finance, 53, 1061-1082.

Golub, S. J. ve Huffman, H. D. (1984). Cash flow, why it should be stressed in financial reporting. Financial Executive, $52,34-40$.

Habib, A. (2010). Prediction of operating cash flows: Further evidence from Australia. Australian Accounting Review, $20(2), 134-143$

Hales, J. ve Orpurt, S. F. (2013).A review of academic research on the reporting of cash flows from operations. Accounting Horizons, 27(3), 539-578.

Krishnan, G. V. ve Largay III, J. A. (2000). The predictive ability of direct method cash flow information. Journal of Business, Finance \& Accounting, 27, 215-245.

Nurnberg, H. (1993). Inconsistencies and ambiguities in cash flow statements under FASB statement No.95. Accounting Horizons, 7(3), 60-75.

Orpurt, S. F. ve Zang, Y. (2009). Do direct cash flow disclosures help predict future operating cash flows and earnings? The Accounting Review, 84(3), 893-935.

Özdemir, S. (2014). Nakit akış tablosunun hazırlanmasında yöntem tartışmaları ve TMS 7 standardı şartlarına uygun brüt (dolaysiz) yönteme göre örnek bir uygulama. Mali Cö̈züm Dergisi, 24(125), 57-76.

Öztürk, E. (2017). Finansal varlıkların ölçme ve muhasebeleștirme esaslarının büyük ve orta boy işletmeler için finansal raporlama standardı ve Türkiye finansal raporlama standartları açısından karşılaştııılması. İșletme Araștrmalar Dergisi, 9(3), 594-617.

Rue, J. C. ve Kirk, F. (1996). Settling the cash flow statement dispute. National Public Accountant, 41, 17-24.

Sun, X. C., Xu, Y.ve Zhao, L. (2018). Does industry affect the cash flow statement presentation format? Accounting and Finance Research, 7(3), 1.

BOBİ FRS http://www.kgk.gov.tr/Portalv2Uploads/files/PDF\%20linkleri/BOB\%C4\%B0\%20FRS.pdf, Erişim Tarihi: 02.02.2019.

BÜYÜK VE ORTA BOY ISSLETMELER IÇİN FINANSAL RAPORLAMA STANDARDI HAKKINDA TEBLİĞ http://www.resmigazete.gov.tr/eskiler/2017/07/20170729M1-1.htm, Erişim Tarihi: 02.02.2019.

TMS

http://www.kgk.gov.tr/Portalv2Uploads/files/DynamicContentFiles/T\%C3\%BCrkiye $\% 20$ Muhasebe $\% 20$ Stan dartlar\%C4\%B1/TMSTFRS2016Seti/TMS7.pdf, Erişim Tarihi: 02.02.2019. 


\section{EXTENDED ABSTRACT}

FRS for LMEs, Turkey subject to independent auditing Financial Reporting Standards (IFRS) in business applications will replace the General Accounting System Application Communiqué. In other words, the financial reporting framework that will be used in the preparation of the financial statements to be submitted to the general assemblies of the companies subject to independent audit and which do not apply Turkey Financial Reporting Standards in accordance with the Turkish Commercial Code will be FRS for LMEs. In addition, since FRS for LMEs will establish a benchmark in the independent audits of all companies subject to independent auditing except for Public Interest Institutions in general, it will be an important step for our country in terms of providing financial reporting and independent auditing at international standards. FRS for LMEs entered into force on the date of its publication to be applied in accounting periods starting on 1/1/2018 and after (Arar, 2018, p. 8-9). The FRS for LMEs set contains some of the features of both General Accounting System Application Communiqué and Turkey Financial Reporting Standards. In other words, the current accounting system, together with the FRS for LMEs, converged slightly to the principles and practices of Turkey Financial Reporting Standards. However, there is still no full compliance with the Turkey Financial Reporting Standards (Öztürk, 2017, p. 597).

For example, in the B Conceptual Framework Financial Statements "section of the standard, the tables that are required to be regulated as a minimum by companies subject to FRS for LMEs (a) Statement of Financial Position (b) Statement of Profit or Loss (c) Statement of Cash Flows (d) Statement of Changes in Shareholders' Equity and (d) They are defined as footnotes (FRS for LMEs: 1). When the financial statement basket defined in FRS for LMEs and the financial statement basket defined in Turkey Financial Reporting Standards are compared, it is seen that the "Other Comprehensive Income Statement defined in Turkey Financial Reporting Standards is not defined in the FRS for LMEs standard. When the contents of the financial statements in FRS for LMEs and Turkey Financial Reporting Standards are examined, it is possible to find other differences. For example, there is no provision or recommendation as to the method (direct - indirect method ') of the Cash Flow Statement described in Section 2 of the FRS for LMEs. However, when the IFRS 7 Cash Flow Standard in Turkey Financial Reporting Standards is examined, it is stated in Article 19 that Businesses are encouraged to use the direct method in reporting their cash flows from their main activities." This difference is the main basis of the study. In this study, first of all, it is aimed to determine the advantages and disadvantages of "Direct" or "Indirect" methods that companies prefer to use in preparing their cash flow statements. Cash flow statement is a statement of cash flows arising from cash flow activities, investment activities and financing activities for the period (FRS for LMEs, p. 13). According to another definition, the entity's inflows and outflows in cash or cash equivalents within a reporting period, their sources and usage places (Arar, 2018, p. 22).

Cash refers to cash and demand deposits in the entity. Cash equivalents are short-term investments with high liquidity, the amount of which is easily convertible to a certain amount of cash and the risk of change in value is insignificant. Cash equivalents are held for fulfilling short-term cash commitments rather than for investment or other purposes. When an investment has a short term (for example, three months or less from the date of acquisition), it is generally considered as cash equivalent (Arar, 2018, p. 23). In the application part of the study, it is aimed to create an application guide and provide a comparison environment for the enterprises by means of cash flow tables to be prepared both by direct method and by indirect method through the same sample enterprise. There are many studies in the literature that using direct method in cash flow statement will be more beneficial for related parties. However, it has been determined that indirect method is more widely used because of its understandable simple structure, ease of preparation and the desire of enterprises not to share much financial information with the public. In the implementation study, it is seen that the Cash Flows from Main Operations "section of the cash flow statement prepared by direct method provides more detailed financial information than the indirect cash flow statement. In addition, the cash flow statement prepared by indirect method has a more simple and understandable structure. This supports the aforementioned reasons for the more preferred method of indirect method. However, in the Cash Flows from Investment Activities" and Cash Flows from Financing Activities" sections of both methods, the same financial information is included and there is no difference between the methods. In this study, the advantages and disadvantages of the cash flow tables and the methods presented for the enterprises that will use FRS for LMEs are presented comparatively; an application guide was created. 